\title{
Evaluasi Usability dan Perbaikan Desain Aplikasi Mobile Menggunakan Usability Testing dengan Pendekatan Human-Centered Design (HCD)
}

\author{
Doni Abdul Fatah \\ Teknik Informatika, Universitas Trunojoyo Madura \\ doni.fatah@trunojoyo.ac.id \\ DOI: https://doi.org/10.21107/rekayasa.v13i2.6584
}

\begin{abstract}
Usability Evaluation and Improvement of Mobile Application Design Using Usability Testing with a Human-Centered Design (HCD) Approach

ABSTRACT

Meteorology, Climatology, and Geophysics (BMKG) mobile application is an application that provides weather early warning. The early warning information is not only limited to the province, but also to the sub-district level. But when the information displayed in the application is still not clear enough to be understood by the user and the ease and comfort of the user is not in accordance with the purpose of making the application, it is necessary to redesign the BMKG mobile application by referring to the 8 rule guidelines (Eight Golden Rules) for interaction design, as well as testing using SUS Usability Questionnaire (System Usability Scale) which contains 10 questions related to the application by conducting interviews with respondents of the application, from the results obtained in testing using the principles of the Eight Golden Rules there are three points that have not been maximal starting from Design dialogue to yield closure, Internal Support locus of control, and internal support locus of control, then testing using SUS is done twice, for the first to the original design of the BMKG mobile application with an average score of 60 shows the level of acceptance of Marginal Low users, while the grade scale is in the D category d an Adjective rating category $\mathrm{OK}$, from the results of the proposed improvement design in accordance with the input that has been obtained from respondents then the second test with the SUS Calculation method to get an average score of 80.25 can be concluded on the acceptability ranges included in Acceptable, on the grade scale get a value of B, and for Adjective Rating included in Excellent, so that the proposed BMKG mobile application design can be used easily and users do not feel confused about the design of the results of improvements to get weather information services provided.
\end{abstract}

Keywords: Eight Golden Rules, Interaction, Mobile, System Usability Scale, Usability

\section{ABSTRAK}

Aplikasi mobile Badan Meteorologi, Klimatologi, dan Geofisika (BMKG) merupakan aplikasi yang memberikan peringatan dini cuaca. Informasi peringatan dini tersebut skalanya tidak hanya sebatas provinsi, tetapi hingga tingkat kecamatan. Namun ketika informasi yang ditampilkan dalam aplikasi masih kurang jelas untuk dipahami pengguna serta kemudahan dan kenyaman pengguna belum sesuai tujuan pembuatan aplikasi maka perlu dilakukan redesign pada aplikasi mobile BMKG tersebut dengan mengacu pada 8 rule panduan (Eight Golden Rules) untuk desain interaksi, serta pengujian menggunakan Kuesioner Usability SUS (System Usability Scale) yang berisi 10 pertanyaan terkait aplikasi dengan melakukan wawancara kepada responden terhadap apikasi tersebut, dari hasil yang didapatkan pada pengujian menggunakan prinsip Eight Golden Rules terdapat tiga point yang belum maksimal mulai dari Design dialogue to yield closure, Support internal locus of control, dan Support internal locus of control, kemudian pengujian menggunakan SUS yang dilakukan secara 2 kali, untuk yang pertama terhadap desain asli dari aplikasi mobile BMKG dengan skor rata-rata 60 menunjukan tingkat penerimaan pengguna Marginal Low, sedangkan grade skala masuk kategori D dan Adjective rating kategori OK, dari hasil dilakukan usulan desain perbaikan sesuai dengan masukan yang telah didapatkan dari para responden kemudian pengujian yang ke dua dengan metode Perhitungan SUS mendapatkan skor rata-rata 80,25 dapat disimpulkan pada acceptability ranges masuk dalam Acceptable, pada grade scale mendapat nilai B, serta untuk Adjective Rating masuk dalam Excellent, sehingga usulan desain aplikasi mobile BMKG dapat digunakan dengan mudah dan pengguna tidak merasa kebingungan terhadap desain hasil perbaikan untuk mendapatkan layanan informasi cuaca yang diberikan. Kata Kunci: Eight Golden Rules, Interaksi, Mobile, System Usability Scale, Usability

\section{PENDAHULUAN}

Pada perkembangan jaman ini seseorang butuh informasi cuaca untuk menentukan suatu pekerjaan. Tak jarang mereka sering kali mendownload aplikasi untuk melihat perkiraan

\section{Article History:}

Received: January, 28 ${ }^{\text {th }}$ 2020; Accepted: May, $10^{\text {th }} 2020$

REKAYASA ISSN: 2502-5325 has been Accredited by Ristekdikti (Arjuna) Decree: No. 23/E/KPT/2019 August $8^{\text {th }}$, 2019 effective until 2023 cuaca hari ini, esok atau minggu depan. Badan Meteorologi, Klimatologi, dan Geofisika (BMKG) (BMKG, 2016) telah meresmikan kehadiran aplikasi mobile "Informasi Cuaca Indonesia" untuk ponsel pintar Android. Diharapkan kehadiran aplikasi Informasi Cuaca Indonesia ini

\section{Cite this as:}

Fatah, D.A. (2020). Evaluasi Usability dan Perbaikan Desain Aplikasi Mobile Menggunakan Usability Testing dengan Pendekatan Human-Centered Design (HCD). Rekayasa, 13(2), 130-143. https://doi.org/10.21107/rekayasa.v13i2.6584 
dapat menjawab kebutuhan masyarakat terhadap informasi cuaca dari BMKG secara mudah.

(Shneiderman B. \& Diakopoulos, 2016) Sesuai panduan proses pembuatan suatu rancangan antarmuka atau user interface untuk suatu desain interaksi, 8 rule panduan tersebut mengenai desain interaksi yang dipakai hampir diseluruh dunia, yang mana ketika mendesain sebuah aplikasi harus dapat memenuhi 8 point mulai dari Konsistensi, Shortcut, Feedback, Dialog Closure, Simple Error Handling, Reversible Actions, Put User In Control, Reduce Short-Term Memory Load, (Sabandar \& Santoso, 2018), (Shneiderman B. \& Diakopoulos, 2016) sehingga aplikasi yang dibuat akan menjadi lebih mudah digunakan dan dapat menghindari terjadinya kebingungan pada para user.

Melihat permasalah yang terdapat pada Aplikasi Mobile BMKG yang mengacu pada desain interface (Eight Golden Rules) ditemukan beberapa hal mulai dari letak kekurangan aplikasi ternyata pesan kesalahan seperti misalnya jika aplikasi pernah dibuka lalu ditinggalkan, saat kembali dengan kondisi tidak terkoneksi ke internet maka saat dilakukan refresh tidak akan menampilkan apa-apa hanya animasi loading beberapa saat kemudian menghilang tanpa memberi tampil apa-apa. Dari segi user control, aplikasi ini sangat minim sekali atau dapat juga dikatakan nyaris tidak bisa, hanya dua akses yang diberikan pada user yaitu untuk mengubah lokasi perkiraan default dan notifikasi peringatan cuaca kota mana yang ingin ditampilkan. Selebihnya user hanya memiliki fungsi view saja, dalam hal ini aplikasi Info BMKG sudah berusaha untuk memenuhi poin ini, namun masih kurang dalam hal penataan letak isi dari Dashboard. Pada beranda ditampilkan 4 baris statistik utama dalam info cuaca Indonesia, di mana masing-masingnya hanya dipisahkan dengan nuansa warna yang berbeda sehingga user untuk pertama kalinya akan kesulitan fokus pada satu topik tertentu karena kesannya bercampur. Dan juga user tidak diberikan akses untuk mengubah topik apa yang mereka ingin ketahui pada tampilan Dashboard.

Perlu kita ketahui juga bahwa usability merupakan daya guna atau kemudahan pengguna dalam menggunakan suatu tools atau alat dalam mencapai tujuanya atau melakukan kegiatan dan utility merupakan kemampuan sebuat aplikasi BMKG untuk memberikan manfaat, kegunaan atau kepuasaan kepada pengguna. Dengan begitu kami ingin membuat sebuah perbaikan pada beberapa fitur aplikasi BMKG agar bisa memaksimalkan tujuan dari pembuatan aplikasi BMKG dan kenyaman untuk user. Beberapa permasalahan yang dibahas pada penelitian ini diantaranya adalah pengguna BMKG merasa kesulitan dengan tampilan dashbord yang membingungkan. Solusi yang diharapkan pada permasalahan ini adalah desain perbaikan (redesain) perlu dilakukan agar aplikasi BMKG bisa terlihat sederhana dan tidak membingungkan. Permasalahan selanjutnya adalah tentang pengguna BMKG merasa kesulitan dengan pengaturan yang membingungkan karena pada tampilan User Interface (UI) hanya ada set lokasi saja. Usulan desain perbaikan perlu dilakukan agar aplikasi BMKG bisa memberikan user kenyamanan dalam memilih set yang banyak (tidak hanya set lokasi)

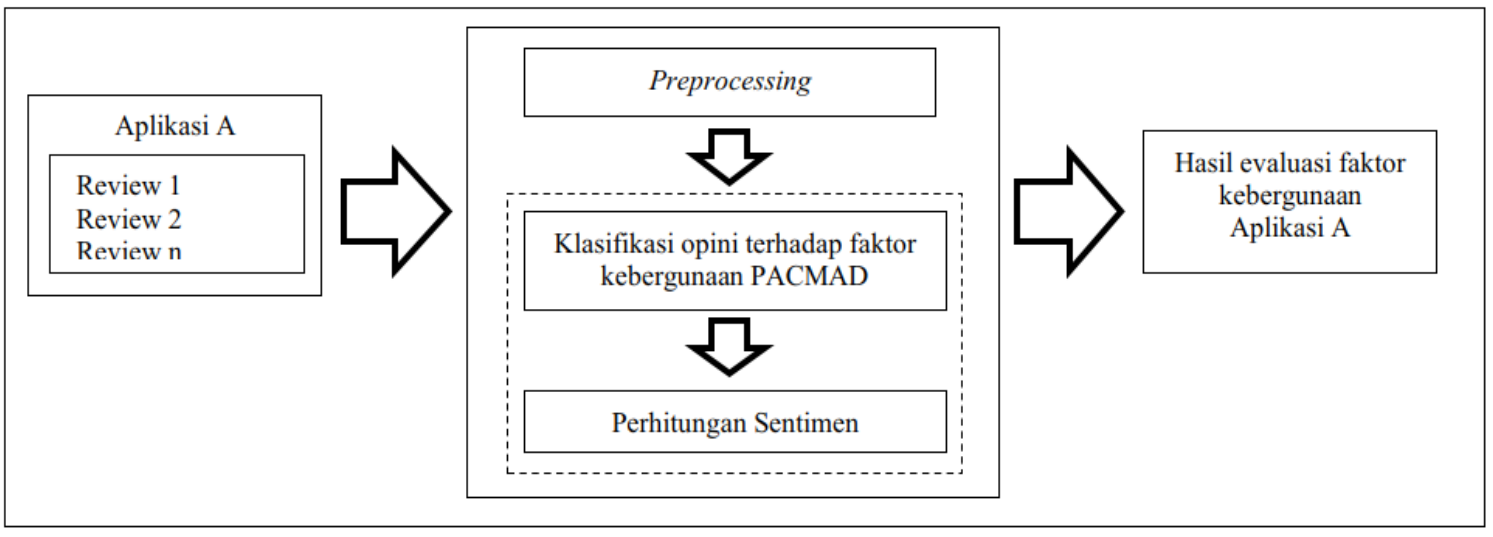

Gambar 1. Contoh data review pengguna (Wardhana et al., 2016). 


\section{TINJAUAN PUSTAKA}

Beberapa penelitian-penelitian penunjang sebelumnya yang pernah dilakukan terkait dengan penelitian yang sedang dilakukan.

(Wardhana, Purwitasari, \& Rochimah, 2016) Pada penelitiannya melakukan Analisis Sentimen terhadap Review Pengguna pada Aplikasi Mobile Untuk mengevaluasi Faktor Usability beberapa proses dilakukan preprocessing, klasifikasi faktor usability, dan perhitungan sentimen sedangkan untuk keluaran adalah nilai hasil evaluasi dari setiap faktor usability yang diujikan.

Dengan mempertimbangkan tingkat sentimen review pengguna nilai evaluasi yang dihasilkan lebih efektif serta sesuai dengan faktor usability yang diulas oleh pengguna. Berdasarkan hasil pengujian yang dilakukan, nilai akurasi klasifikasi yang diperoleh adalah $82 \%$ dan nilai akurasi sentimen yang diperoleh adalah $79 \%$.

(Akhsan \& Faizah, 2017) Pada penelitiannya memaparkan beberapa tahapan-tahapan mengenai tata cara perancangan desain chatbot yang berdasarkan UCD (user centered design). Pertama Understanding, disini yang dimaksud yaitu pemahaman antara masalah chatbot yang ada pada pasaran saat ini. Dilakukan usability testing dengan metode SUS yang sederhana. Kedua Define tahapan dimana mempersiapkan strategi penyelesaian setelah memahami berbagai permasalahan yang ada pada sistem chatbot marketplace saat ini. Ketiga Diverge tahapan untuk mendapat ide-ide sebanyak mungkin untuk merancang sebuah produk atau program yang mengacu dari hasil Analisa tahapan define. Keempat Decide memutuskan ide apa saja yang akan dipakai untuk dilanjutkan pada tahapan selanjutnya. Kelima Prototype pengimplementasian ide-ide dalam sebuah rancangan dasar yang nantinya bisa ditingkatkan menjadi program akhir. Terakhir yaitu validate, untuk menguji hasil dari prototype dengan tujuan untuk menemukan apa yang kurang dari prototype yang dibuat oleh tim. Pengujian dilakukan dengan melakukan usability testing pada prototype chatbot baru sebanyak lima partisipan yang berbeda digunakan setiap chatbot pada saat usability testing. Hasil usability testing chatbot baru kemudian dibandingkan dengan chatbot lama. Diperoleh skor SUS (System Usability Scale) chatbot baru sebesar 70,5 . Skor tersebut meningkat sebanyak 18,4 secara rata-rata dari chatbot lama (Akhsan \& Faizah, 2017).

(Yatana Saputri, Fadhli, \& Surya, 2017) Pada penelitian ini dilakukan pada E-Commerce Putri Intan Shop Berbasis Web. Web ini adalah milik dari sebuah badan usaha yang bergerak pada bidang kecantikan. Pada penelitian menggunakan metode Black box testing, metode ini berfokus pada persyaratan fungsional sistem mulai dari fungsi dan menu yang tersedia. Pengujian ini diambil bersamaan dengan pengambilan data untuk usability testing. Metode selanjutnya yaitu 5 second Testing, adalah sebuah metode yang berdasarkan dari pengalaman 5 detik pertama yang kita dapat dari mengakses desain tersebut. Dengan menggunakan 33 responden anonym maka mendapatkan data 25 yang nantinya hasilnya dapat berupa prosentase total. Metode terakhir yaitu Usability testing dengan penghitungan skala likert. Berdasarkan Usability Testing dengan System Usability Scale, mendapatkan range excellent sebesar $86,8 \%$. Sehingga berhasil membangun sistem yang user-friendly dengan tingkat usability yang tinggi. Berdasarkan 5 second testing, rata-rata persentase $80 \%$ menunjukan keberhasilan memberikan kesan dan diterima pengguna dalam waktu 5 detik.

(Brooke, 2014) Penelitian selanjutnya menjelaskan tentang dasar dasar dari Usability scale dan juga pengaplikasiannya, dalam jurnal ini dibahas mengenai bagaimana cara mengukur tingkat keefektifan dan kepuasan manusia dalam menggunakan sebuah perangkat lunak. Masalah muncul karena sejatinya sebuah perasaan tidak memiliki alat pengukuran yang pasti, digunakanlah yang namanya pendekatan konteks berupa Skala Likert. Adapun sumber data didapat dari kuisioner bentuk semacam pertanyaan seputar seberapa puaskah user terrhadap sesuatu misalnya mengenai tingkat kesulitan dalam mengoperasikan perangkat lunaknya. Lalu disediakan jawaban berupa skala untuk mengukurnya, misalnya dimulai dari sangat sulit, sulit, sedang, mudah dan sangat mudah. Setelah mendapatkan respon dari User, 
maka sebenarnya dari masing-masing jawaban pada skala tersebut memiliki nilai, misalnya sangat sulit bernilai 1 , sulit bernilai 2 , sedang bernilai 3, mudah bernilai 4 dan sangat mudah bernilai 5. Dari jawaban User tersebut semuanya dijumlahkan, lalu jumlah tersebut dikalikan dengan 2.5 untuk mendapatkan nilai secara keseluruhan dalam mengukur System Usability yang bisanya memiliki rentang dari 0 hingga 100 . (Akbar, Kaburuan, \& Effendy, 2018), Penelitian ini akan mendesain aplikasi yang menjadwalkan aktifitas untuk anak yang berkebutuhan khusus. Langkah awal yang lakukan adalah mengecek konteks atau target user yang akan memakai aplikasi ini. Didapatkan 5 sampel yaitu PC1, PC2,PC3,PC4 dan PC5. Hasil dari mengumpulkan informasi yaitu anak anak berumuran 7- 12 tahun mudah untuk memahami sesuatu. Lalu langkah kedua yang dilakukan adalah Spesifikasi Requirements, beberapa keluhan/kebutuhan dari user akan dimasukkan kedalam requirement dalam bentuk fitur-fitur. Produce Desain solution, Dari data yang telah terkumpul mendesain User interface yang terbentuk dari saran dan kebutuhan daripada pengguna, yang telah terdefinisikan dalam bentuk requirements. Design Evaluation 1, adalah dimana mengevaluasi hasil dari desain yang telah dikerjakan selama ini dengan metode Quality in use Integrated Measurament (QIUM). System Satisfies adalah tahapan dimana hasil akhir dari sistem yang telah dikerjakan telah final maka akan mendapatkan beberapa feedback dalam bentuk prosentase yang dimana kalau dibawah 85\% itu terbilang rendah (Akbar et al., 2018).

(Laily, Rokhmawati, \& Herlambang, 2018) Pada penelitiannya mengevaluasi dan perbaikan website Djarum Beasiswa Plus dengan pendekatan HCD (Human-Centered Design) dengan analisis konteks penggunaan, kebutuhan pengguna, pembuatan desain solusi serta evaluasi desain solusi yang melibatkan 47 responden yang mengaku merasa kesulitan dalam mencapai tujuannnya sebelum dilakukan desain perbaikan pada interface website djarum beasiswa plus, tetapi setelah dilakukan desain perbaikan mendapatkan hasil nilai usability lebih tinggi mulai dari aspek efektivitas dengan tingkat keberhasilan $100 \%$, aspek efisiensi ratarata waktu pengerjaan jauh lebih cepat dari 29,49 detik menjadi 06,30 detik, pada aspek kepuasan pengguna menyatakan lebih memilih tampilan desain solusi dikarenakan lebih mudah dalam mencapai tujuan (Laily et al., 2018).

(Santoso, Schrepp, Yugo Kartono Isal, Utomo, \& Priyogi, 2016) Pada objek penelitian ini yaitu mengukur pengalaman pengguna dari lingkungan e-Learning yang berpusat pada siswa. Permasalahannya yaitu untuk mengembangkan versi pengguna yang disesuaikan. Sumber data didapatkan dari 213 mahasiswa ilmu computer. Solusi dari permasalahan yang ada yaitu peneliti menggunakan sistem yang bernama SCELE didalamnya melakukan penelitian meliputi pengalaman pengguna, pengukuran, pembelajaran yang berpusat pada siswa, manajemen pembelajaran sistem, dan pembelajaran online.

(Junus, Santoso, Isal, \& Utomo, 2015) Objek Dalam penelitian ini yaitu, pengujian kegunaan dilakukan untuk SceLE, menargetkan kegiatan pembelajaran yang dilakukan oleh mahasiswa sarjana di Fasilkom UI, dalam bentuk blended mode online learning. Permasalahannya adalah Untuk mengetahui pengalaman belajar mahasiswa dan dosen di SceLE, untuk mengetahui aspek-aspek yang harus dilestarikan dalam SceLE, untuk mengetahui aspek-aspek yang wajib ditingkatkan dalam SCeLE bersama dengan langkah-langkah yang diperlukan (Junus et al., 2015). Solusinya adalah untuk mencapai tujuan ini, penelitian ini berfokus pada fitur utama di SCeLE yang memiliki koneksi langsung ke proses pembelajaran halaman kursus dan halaman depan.

(Farooqui \& Rana, Tauseef, Jafari, 2019) Penelitian ini dilakukan untuk mengetahui seberapa besar dampak melibatkan user dalam sebuah proses pengembangan suatu aplikasi. penelitian ini muncul karena adanya rasa khawatir terhadap aplikasi yang telah dibuat jika dilakukan tanpa melibatkan user sama sekali. User Experience (UX) sangatlah penting dalam proses pembuatan aplikasi, karena dengan itu bisa diketahui apa saja yang menjadi masalah ataupun apa saja yang diinginkan user itu sendiri, karena nanti pada akhirnya setelah aplikasi tersebut jadi, yang akan beriteraksi secara terus menerus dalam kehidupan sehari- 
harinya adalah user itu sendiri. Untuk meningkatkan usability dan UX ini pastinya kita memerlukan data. Data ini bisa didapatkan dari hasil perbincangan atau wawancara dengan user secara langsung. Misalnya menanyakan tentang apa aktivitas kesehariannya, dan kira-kira dengan aplikasi ini harapannya apa terkait dengan aktivitas kesehariannya tersebut. Dari seputar pertanyaan - pertanyaan di atas lalu dibuatkanlah sebuah Persona agar dapat dengan mudah kita pahami untuk kemudian membuat sebuah permodelan untuk menguji apakah dalam kondisi realnya sudah sesuai antara Persona dari User tersebut dengan hasil prototype yang telah dibuat. Setiap kali menerbitkan prototype, dilakukan percobaan kembali terhadap user tersebut atau proses evaluasi yang nantinya akan mendapatkan kembalian berupa feedback. Begitu seterusnya hingga antara user dan aplikasi tersebut sesuai dan pada akhirnya barulah terbitlah versi finalnya.

(Forte, Jonas, Darin, 2017) Penelitian ini membahas mengenai studi kasus sebuah aplikasi rental sepeda aplikasi mobile outdoor yang mana akan dilakukan beberapa evaluasi terhadap aplikasi tersebut terutama dalam Interface/antar muka demi terwujudnya User Experience (UX) yang lebih baik. Terkadang pada saat membuat sebuah aplikasi dan langsung menerbitkannya berdasarkan intuisi kita dapat diperkirakan akan ada banyak sekali ketidak sesuaian yang terjadi bila dibandingkan dengan melibatkan peran User di dalamnya. Namun masalah ini masih bisa diatasi misalnya dalam kasus pada penelitian ini dilakukan evaluasi dengan cara analisis dengan mengobservasi kebiasaan user saat berinteraksi dengan UI. Dibuatkanlah beberapa lagi dan kemudian membiarkan User yang memberikan penilaian atau feedback. Antarmuka yang manakah yang sesuai dengan konteks penggunaan mereka. Proses redesign atau perubahan desain akan dilakukan berdasar pada pelibatan user dan evaluasi prototype. Adapun metode - metode yang dilakukan, pertama melakukan studi objek yang mana dalam hal ini tentu yang menjadi objeknya adalah aplikasi rental sepeda tersebut. Kedua menandai atau memberikan ciri pada bagian-bagian antar muka yang akan dilakukan evaluasi. Ketiga merancang permodelan dengan susunan evaluasi UX, analisa UX, merancang ulang aplikasi dan melakukan validasi terhadap prototype. Keempat meningkatkan kemanan aplikasi dan jadilah sebuah prototype yang akan dilakukan percobaan terhadap User. Namun tidak berhenti sampai di sini, ada hal - hal lain yang perlu dilakukan juga seperti melakukan kuisioner secara online, membuka masukan atau feedback dari kolom komentar dan dari hasil data - data tersebut dilakukan diskusi lebih lanjut sehingga menghasilkan sebuah aplikasi yang dapat digunakan secara publik.

(Rahadi, 2014) Penelitian ini menganalisis aplikasi android memiliki akseptabilitas berdasarkan kriteria usability dengan menggunakan kuesioner sebagai instrumen penelitian yang terdiri diberikan kepada 25 responden yang terdiri dari dosen, staff karyawan, dan mahasiswa, dengan 13 pertanyaan yang dikelompokan menjadi 5 variabel usability mulai dari 1) login kedalam sistem sebagai user admin, kemudian logout dan lakukan login kembali, 2) Login kedalam sistem sebagai user admin, kemudian logout dan lakukan login kembali, 3) Mengisi form pada Menu Support untuk pencarian aplikasi android, 4) Menambah, mengubah dan menghapus data aplikasi android pada halaman admin, 5) Mencari informasi update dalam aplikasi web (Rahadi, 2014). Dari 5 variabel aplikasi android belum memenuhi 4 variabel lainnya dapat disimpulkan bahwa aplikasi android belum memenuhi kriteria-kriteria usability, tetapi nilai penerimaan usability oleh user berada di atas angka 3 dalam skala 5 dengan yang paling dominan adalah kenaikan tingkat usability mudah diingat dan menaikan tingkat akseptabilitas aplikasi android.

(Nurhadryani, Sianturi, Hermadi, \& Khotimah, 2013) Pada penelitian ini melakukan pengujian usability pada aplikasi M-Breakfast Nutrition aplikasi rekomendasi menu sarapan sesuai profile pengguna dengan menggunakan metode field observation yaitu dengan mengobservasi pengguna tentang penggunaan aplikasi dengan komponen yang diuji efektivitas, efisiensi dan kepuasan.

(Nurhadryani et al., 2013) Pengujian dilakukan dengan lembar skenario, lembar pengamatan dan kuesioner dengan responden siswa kelas 6 


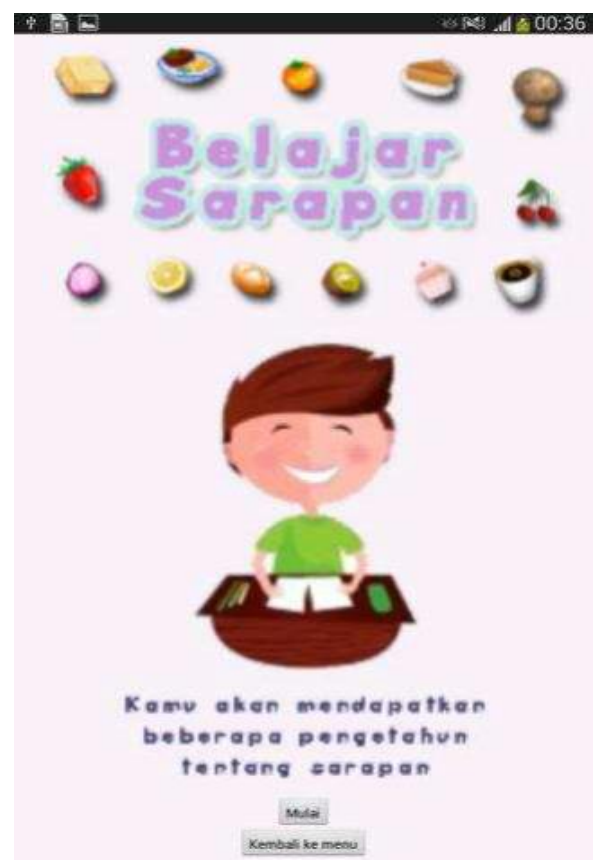

Gambar 2. Interface aplikasi M-Breakfast Nutrition (Nurhadryani et al., 2013)

SD yang berjumlah 20 siswa yang terdiri dari $55 \%$ siswa perempuan dan $45 \%$ siswa laki-laki, hasil pengujian usability pertama diperoleh nilai $78,4 \%$ masukan tingkat effisiensi, efektivitas dan kepuasan pengguna, pengujian usability ke 2 menunjukan peningkatan usability sebesar 91,1\% menunjukan pengujian usability penting dilakukan untuk pengembangan aplikasi dengan mendapat masukan langsung pengguna dan meningkatkan nilai usability pada aplikasi sehingga dapat diterima oleh pengguna.

\section{METODE PENELITIAN}

Penelitian ini melibatkan beberapa responden mulai dari mahasiswa, swasta dan dosen yang mereka semua ada yang baru memakai, dan pengguna baru, dengan menggunakan metode pengukurannya adalah sebagai berikut

Melakukan analisis terhadap desain interaksi sistem yang sudah ada, dalam melakukan analisis dengan cara memahami fitur-fitur dan cara kerja aplikasi yang diteliti (Handiwidjojo \& Ernawati, 2016), (Rasmila, 2018). Kemudian merumuskan asumsi permasalah terkait interface dan usability berdasarkan permasalahan yang diamati oleh pengguna dengan cara melakukan wawancara terkait apa yang dirasakan ketika menggunakan aplikasi, kemudian mencari literatur atau referensi penunjang yang berkaitan dengan penelitian terkait sehingga dapat dijadikan acuan dalam pelaksanaan penelitian (Jelita Ardhiyani, 2015), (Sharfina \& Santoso, 2017), melakukan user research dengan tujuan mengali feedback dari pengguna melalui wawancara kepada pengguna dalam melakukan proses bisnis diaplikasi dari beberapa narasumber kemudian membuat kesimpulan analisis terhadap hasil wawancara yang sudah dilakukan, langkah berikutnya yaitu membuat rancangan desain interaksi secara bertahap mulai dari susunan arsitektur informasi, wireframe atau desain perbaikan (Santoso et al., 2016). Setelah itu membuat skenario usability testing dan melakukan pengujian dengan menggunakan Kuesioner Usability yang berisi 10 pertanyaan terkait aplikasi yang diteliti untuk menguji efektivitas desain baru yang telah dibuat kepada para responden atau end user (Wedayanti, Wirdiani, \& Purnawan, 2019)(Fanani, Lutfi, Ananta Tri , Mahardeka, Candra Brata, 2018).

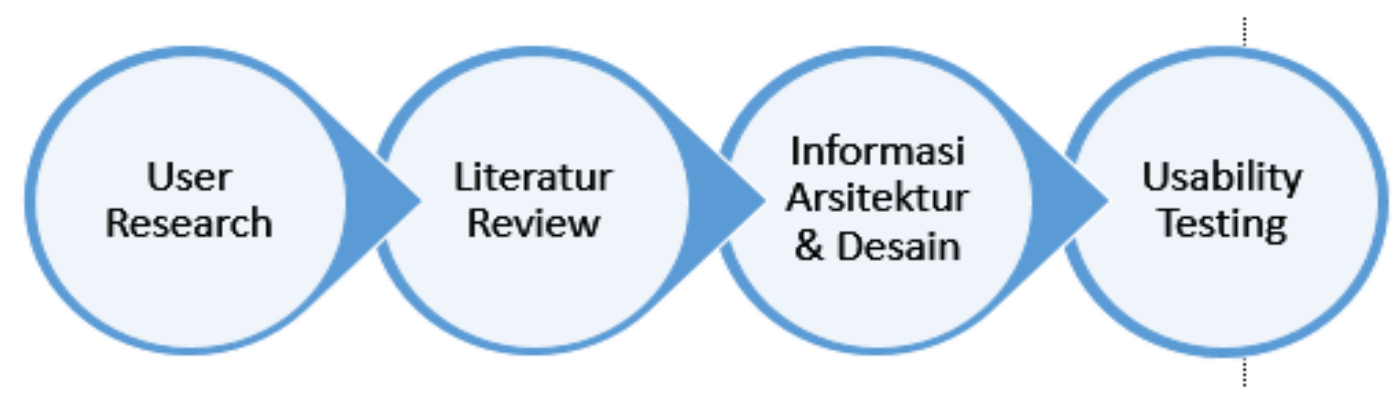

Gambar 3. Metode penelitian 
Tabel 1. Lembar Kuesioner Usability (Sharfina \& Santoso, 2017) (Bangor, Staff, Kortum, Miller, \& Staff, 2009)

\begin{tabular}{|c|c|c|}
\hline No & Intrumen Pertanyaan & Skala \\
\hline 1 & Saya berpikir akan menggunakan sistem ini lagi. & 1 s.d 5 \\
\hline 2 & Saya merasa sistem ini rumit untuk digunakan. & 1 s.d 5 \\
\hline 3 & Saya merasa sistem ini mudah digunakan. & 1 s.d 5 \\
\hline 4 & $\begin{array}{l}\text { Saya membutuhkan bantuan dari orang lain atau teknisi dalam } \\
\text { menggunakan sistem ini. }\end{array}$ & 1 s.d 5 \\
\hline 5 & Saya merasa fitur-fitur sistem ini berjalan dengan semestinya. & 1 s.d 5 \\
\hline 6 & $\begin{array}{l}\text { Saya merasa ada banyak hal yang tidak konsisten (tidak serasi pada } \\
\text { sistem ini). }\end{array}$ & 1 s.d 5 \\
\hline 7 & $\begin{array}{l}\text { Saya merasa orang lain akan memahami cara menggunakan sistem ini } \\
\text { dengan cepat. }\end{array}$ & 1 s.d 5 \\
\hline 8 & Saya merasa sistem ini membingungkan. & 1 s.d 5 \\
\hline 9 & Saya merasa tidak ada hambatan dalam menggunakan sistem ini. & 1 s.d 5 \\
\hline 10 & $\begin{array}{l}\text { Saya perlu membiasakan diri terlebih dahulu sebelum menggunakan } \\
\text { sistem ini }\end{array}$ & 1 s.d 5 \\
\hline
\end{tabular}

Tabel 2. Identifikasi desain interface sesuai prinsip Eight Golden Rules

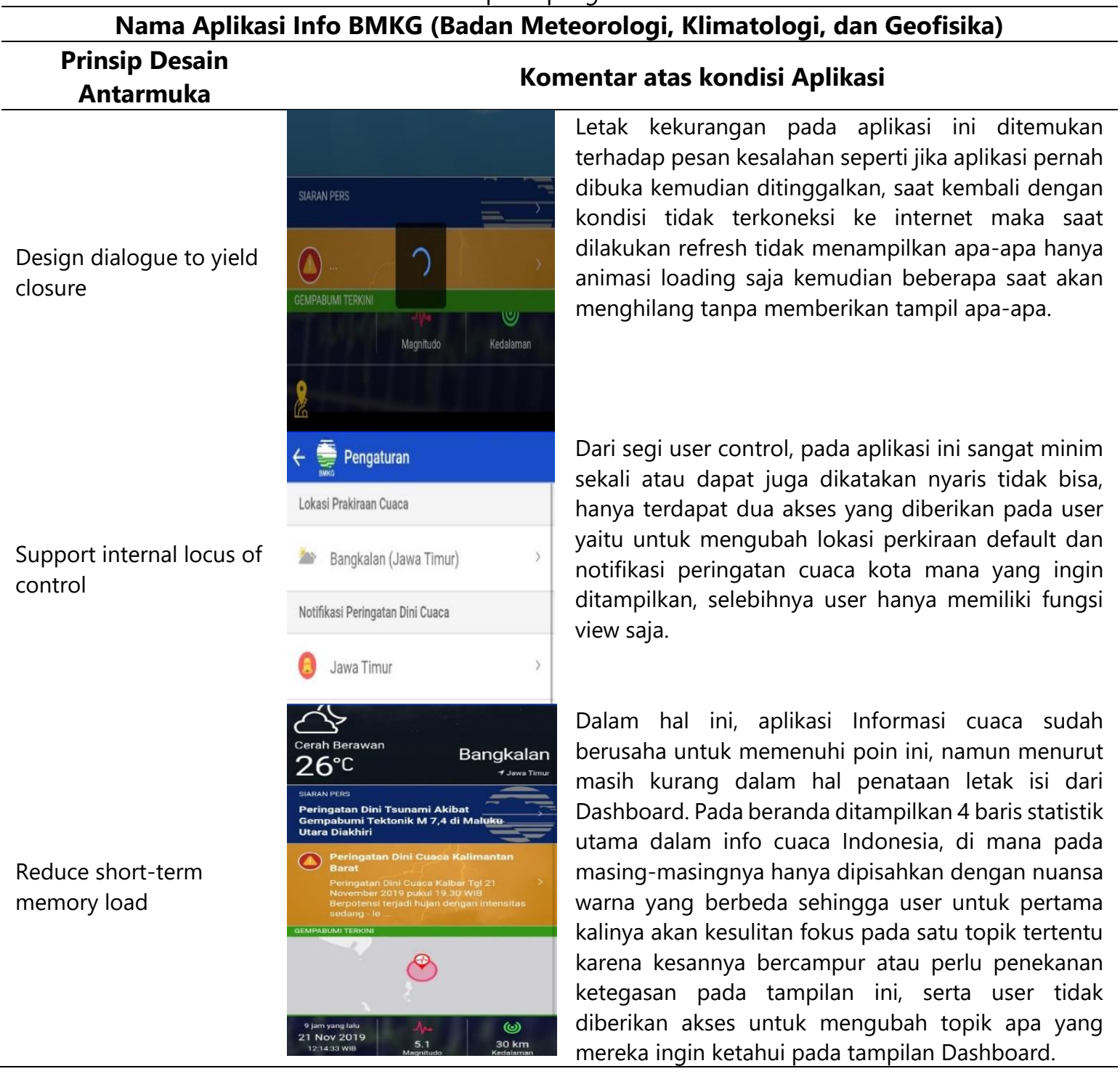


Tabel 3. Kesimpulan Hasil Wawancara dari responden

\begin{tabular}{|c|c|}
\hline Nama Responden & Kesimpulan Hasil Wawancara \\
\hline $\begin{array}{l}\text { M. Habib Nur } \\
\text { Sholahuddin }\end{array}$ & $\begin{array}{l}\text { Narasumber ini sudah memakai aplikasi info BMKG sudah lama dan orang ini } \\
\text { memilih fungsionalitas dan tampilan aplikasi, karena dalam penyampaian } \\
\text { sebuah informasi penting bagi pengguna dan untuk tampilan sendiri juga } \\
\text { sangat penting agar pengguna tetap tertarik menggunakan aplikasi. }\end{array}$ \\
\hline Ahmad Miftahul Ulum & $\begin{array}{l}\text { Narasumber ini baru memakai aplikasi info BMKG memilih untuk ke } \\
\text { fungsionalitas dari aplikasi tersebut. Pernah menggunakan aplikasi lain yang } \\
\text { serupa namun baginya aplikasi Info BMKG lebih lengkap namun tampilannya } \\
\text { masih dikategorikan kurang, dan orang ini pernah melakukan prediksi cuaca } \\
\text { menggunakan instingnya }\end{array}$ \\
\hline Musfirotummamlua'ah & $\begin{array}{l}\text { Narasumber ini sudah lama menggunakan aplikasi Info BMKG. Dalam aplikas } \\
\text { orang ini memilih untuk fungsionalitas dan tampilan dari aplikasi ini merupakan } \\
\text { aspek yang sama penting baginya. Untuk aplikasi Info BMKG perlunya } \\
\text { perbaikan dalam User Interface karena sangat tidak nyaman ketika } \\
\text { menggunakan sebuah aplikasi namun tampilannya yang kurang menarik akan } \\
\text { membuat user cepat bosan. Pengguna juga memilih untuk menggunakan } \\
\text { aplikasi lain jika ada yang lebih baik dari aplikasi Info BMKG }\end{array}$ \\
\hline Nur Azizah & $\begin{array}{l}\text { Narasumber ini baru saja menggunakan aplikasi Info BMKG. Menurut dia } \\
\text { fungsionalitas dan tampilan sama penting baginya karena dalam sebuah } \\
\text { aplikasi harus jelas mengenai informasi apa yang ingin disampaikan dan } \\
\text { tampilan juga harus bagus demi ketertarikan dari pengguna dalam melihat } \\
\text { informasi yang disampaikan. Perlunya perbaikan aplikasi. Orang ini juga pernah } \\
\text { melakukan ramalan cuaca menggunakan instingnya }\end{array}$ \\
\hline Nur Aisyah Fitri & $\begin{array}{l}\text { Narasumber ini sudah lama menggunakan aplikasi Info BMKG. Dia lebih } \\
\text { memilih fungsionalitas karena penyampaian informasi itu penting untuk } \\
\text { disampaikan dengan jelas, untuk aplikasi BMKG ini perlu perbaikan dalam } \\
\text { beberapa fungsi nya. }\end{array}$ \\
\hline
\end{tabular}

Pada tabel 1, merupakan pertanyaan terkait usability aplikasi yang sebelumnya sudah diterjemahkan ke dalam bahasa indonesia pada paper (Sharfina \& Santoso, 2017) dengan penjelasan keterangan STS : Sangat Tidak Setuju, TS : Tidak Setuju, RG : Ragu-ragu, ST : Setuju, SS : Sangat Setuju.

\section{HASIL DAN PEMBAHASAN}

Dengan mengacu pada prinsip Eight Golden Rules maka ditemukan tiga point permasalahan yang perlu dilakukan perbaikan terkait desain interface aplikasi mobile.

Setelah itu dirumuskan tujuan wawancara dengan tujuan agar narasumber memberikan jawaban sesuai dengan apa yang dirasakan terkait aplikasi yang digunakan, langkah ini dilakukan sebelum melakukan wawancara dengan menggunakan 7 point penting sebagai dasar untuk pertanyaan wawancara, dari 7 point tersebut kemudian diuraikan menjadi 24 pertanyaan terkait dengan interface, usability, fungsionalitas, informasi, control user serta pengalaman dalam pengunaannya.

Selanjutnya membuat rancangan desain interaksi secara bertahap mulai dari susunan arsitektur informasi pada aplikasi mobile yang diteliti.

Pada aplikasi mobile BMKG ada 5 menu utama sesuai dengan gambar 4 mulai dari menu Home (Dashboard), menu Cuaca, menu kualitas udara, menu gempa bumu dan menu pengaturan. Dari kelima menu tersebut terdapat fungsi yang berbeda-beda sesuai dengan kebutuhannya, misal pada menu Home (Dashboard) terdapat informasi mulai dari prakiraan cuaca disekitar lokasi pengguna, informasi aktual atau terbaru dari BMKG, peringatan dini terkait dengan cuaca yang terjadi di seluruh Indonesia yang terakir adalah update informasi gempa bumi yang 


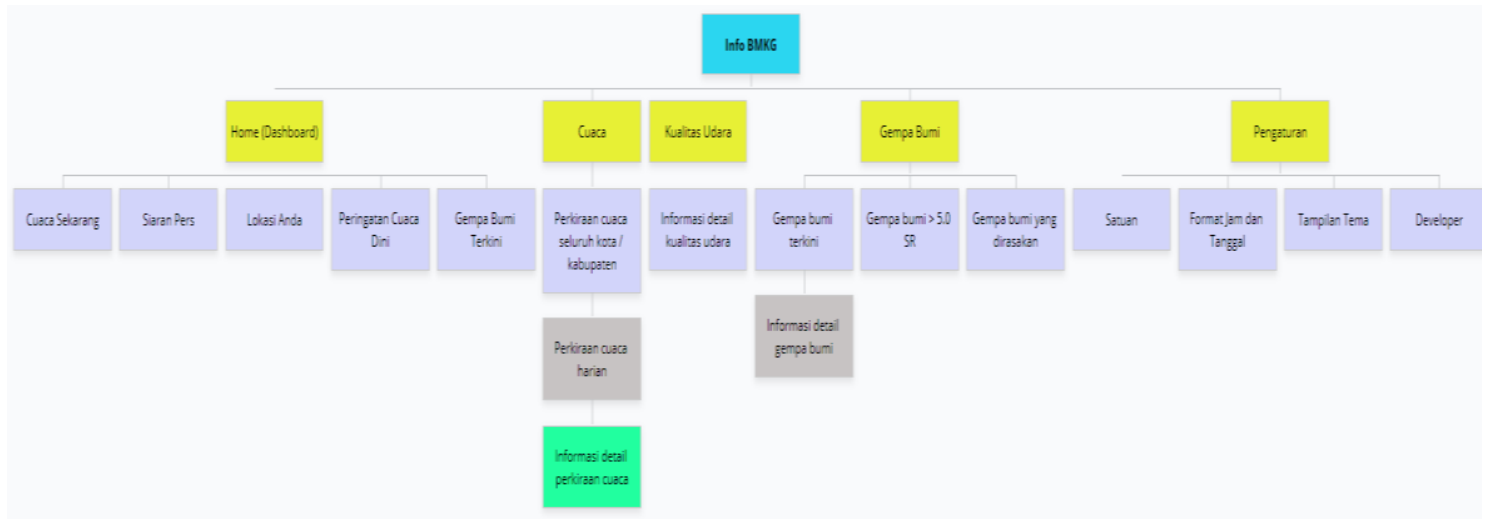

Gambar 4. Information Architecture

terjadi di seluruh Indonesia. Sedangkan pada menu menu Cuaca terdapat informasi tentang prakiraan cuaca untuk seluruh kabupaten, prakiraan cuaca harian dengan 4 waktu mulai dari pagi, siang, malam dan dini hari dan informasi detail prakiraan cuaca meliputi suhu, kelembaban udara dan kecepatan arah angin, untuk menu kualitas udara menjelaskan tentanng informasi detail kualitas udara sesuai dengan skalanya dalam waktu 24 jam, untuk menu gempa bumi terdapat 3 informasi penting didalamnya mulai dari gempa bumi terkini atau terbaru, gempa bumi dengan magnitude $>=5,0$ $\mathrm{SR}$, gempa bumi yang dirasakan dan yang terakir detail informasi gempa bumi mulia dari waktu, skala, kedalaman, lokasi, koordinasi, potensi tsunami hingga jarak titik gempa dengan lokasi pengguna. Kemudian menu yang terakir adalah Menu Pengaturan terdapat menu kontrol untuk user terhadap aplikasi info BMKG, yang meliputi 1) Dapat mengubah satuan cuaca sesuai dengan keinginan. 2). Dapat mengubah format waktu dan tanggal seusai dengan keinginan. 3). Dapat mengubah tema sesuai dengan kenyamanan user. 4). Dan informasi lain seperti tentang pembuat aplikasi, regulasi dan privasi.

Merancang scenario dengan usability testing dengan tujuan untuk mengetahui feedback user terhadapt aplikasi mobile yang digunakan, serta untuk mengevaluasi aplikasi mobile dengan menggunakan skenario sehingga dapat mempermudah menjelaskan dan memprioritaskan fitur yang dimiliki sistem serta bagaimana user dapat mencapai tujuannya. Terdapat 3 tujuan dalam point yang menjadi tujuan skenario mulai dari perkenalan dan menyampaikan tujuan usability testing, mengetahui latar belakang responden, serta mengetahui efektivitas jalannya fitur Perbaikan
Pengaturan, dari ketiga point tersebut didapatkan Hasil Usability Testing, yaitu terdapat 2 kendala dalam penggunaan aplikasi tersebut, yaitu

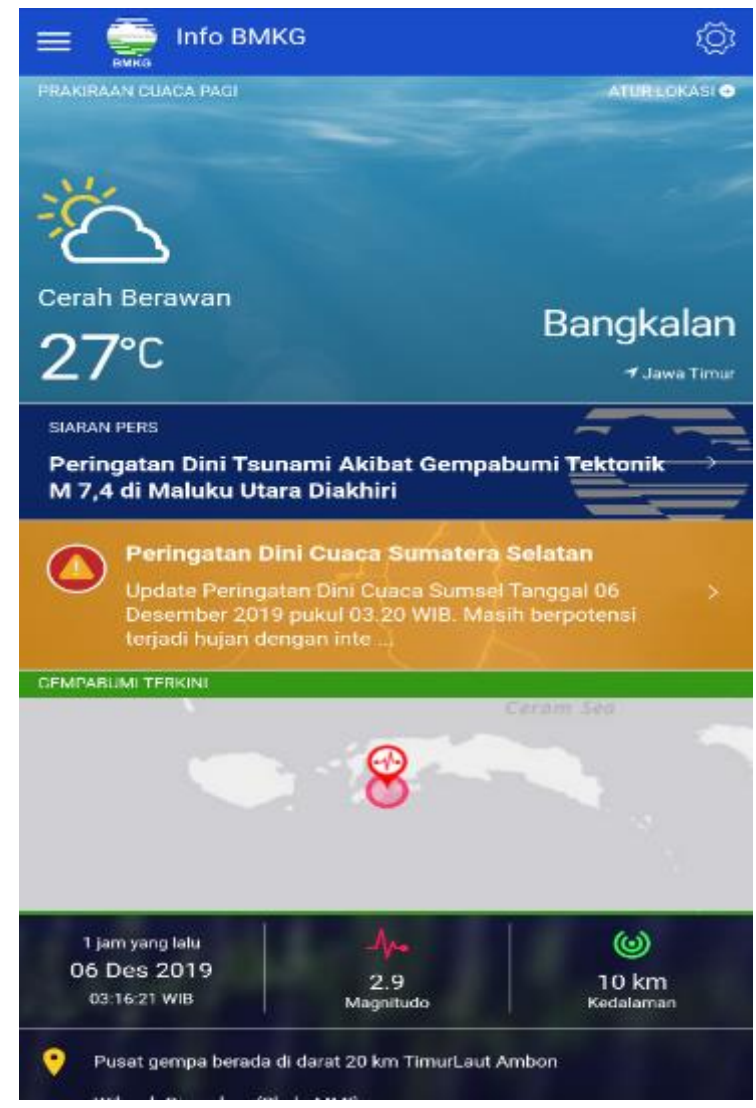

Gambar 5. Tampilan dashboard info BMKG

(BMKG, 2016)

Kesulitan yang dirasakan dalam tampilan dashboard disini user atau pengguna yang tidak biasa dalam melihatnya akan kebingungan karena informasi yang disampaikan belum ada judul yang tegas sehingga membuat user kebingungan. Usulan Perbaikan mengubah tampilan dashboard lebih tersusun rapi, 
kemudian dalam setiap informasi yang disampaikan diberi judul dengan efek lebih tegas.

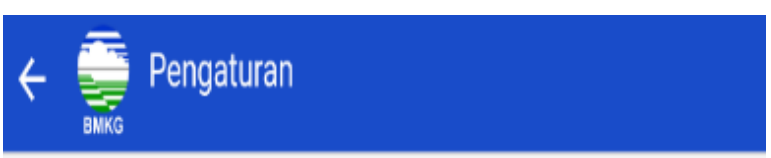

Lokasi Prakiraan Cuaca

\section{Bangkalan (Jawa Timur)}

\section{Notifikasi Peringatan Dini Cuaca}

\section{Jawa Timur}

Gambar 6. Menu pengaturan pada dashboard

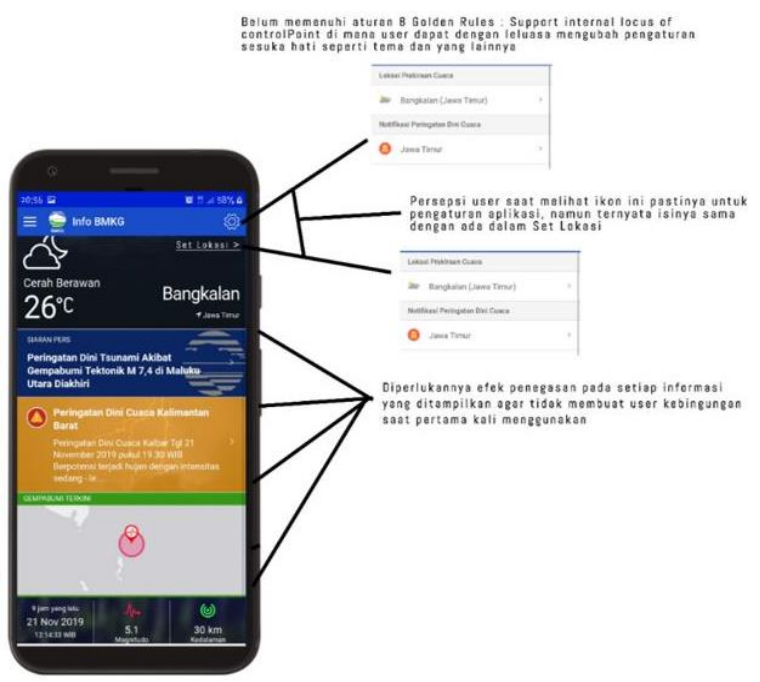

(BMKG, 2016)

Gambar 7. Analisa permasalah dashboard
Kesulitan yang dirasakan dalam icon pengaturan pada dashboard, jika di klik akan masuk ke tampilan pada gambar di atas. Disini si user hanya bisa mengubah tempat lokasi dimana dia berada. Tidak ada fitur lain dalam pengaturan sehingga memberi keterbatasan user dalam mengakses aplikasi. Usulan Perbaikan dalam pengaturan disini berilah fitur pengaturan tambahan yang lebih leluasa, seperti Satuan, Format Jam dan Tanggal, Tampilan Tema, Developer, Syarat dan ketentuan, Privasi dan Tentang kami.

Sehingga dari sini dapat diiustrasikan dalam bentuk desain seperti berikut:

Kemudian dilakukan penilaian dengan menggunakan System Usability Scale yang menggunakan sepuluh standar pertanyaan yang sudah disebarkan kepada responden, didapatkan hasil seperti tabel berikut.

Tabel 4. Hasil penilaian perhitungan SUS ke 1 oleh Responden

\begin{tabular}{ccc}
\hline Responden & Jumlah & $\begin{array}{c}\text { Hasil Penilaian } \\
\text { (Jumlah x 2.5) }\end{array}$ \\
\hline 1 & 21 & 53 \\
2 & 18 & 45 \\
3 & 28 & 70 \\
4 & 24 & 60 \\
5 & 29 & 73 \\
6 & 18 & 45 \\
7 & 29 & 73 \\
Skor Rata-rata (Hasil Akhir) & $\mathbf{6 0}$
\end{tabular}

Berdasarkan aturan metode Perhitungan Skor SUS hasil penilaian responden terhadap Aplikasi Mobile BMKG yang berfokus pada Tampilan Dashbord dan Menu Pengaturan/Setting sesuai pada gambar 1 , sehingga mendapatkan nilai

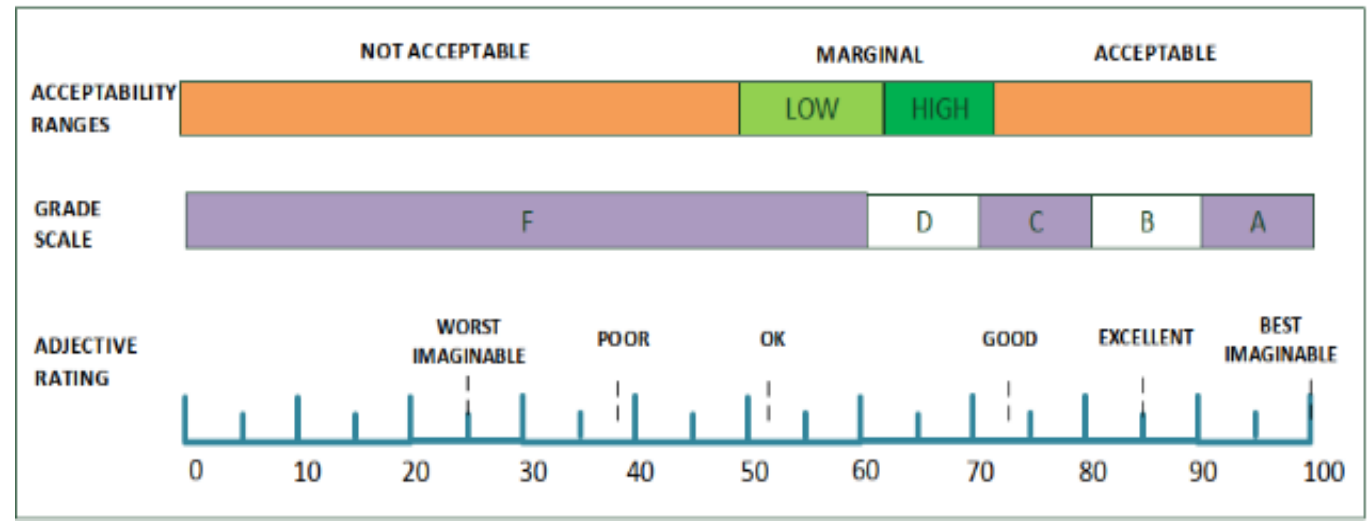

Gambar 8. Standar penentuan skor SUS (Bangor et al., 2009) 
rata-rata dari penilaianan sebesar 60 yang mana dari hasil tersebut dapat ditentukan grade hasil penilaian dapat digunakan menggunakan 2 cara sesuai dengan (Brooke, 2014) yang terdiri dari Acceptability Ranges terdapat tiga kategori mulai dari Not Acceptable, Marginal Low dan High serta Acceptable, untuk grade scale dengan kategori mulai dari A, B, C, D, E dan F dan Adjective Rating terdapat enam kategori mulai dari Worst Imaginable, Poor, OK, Good, Excellent dan Best Imaginable, untuk lebih jelasnya dapat dilihat pada gambar di bawah :

Sedangkan untuk penilaian selanjutnya dengan grade scale mulai dari A, B, C, D dan F sebagai berikut : untuk skor rata-rata responden sebesar 60 untuk Acceptability Ranges, Grade Scale,dan Adjective Rating, untuk Acceptability Ranges masuk Marginal Low, Grade Scale masuk kategori $D$, untuk Adjective Rating masuk dalam grade $O K$, maka untuk hasil penilaiannya pada Aplikasi Mobile BMKG masih perlu desain perbaikan sehingga fitur BMKG menjadi lebih baik dan user merasa nyaman menggunakan aplikasi ini tanpa merasa bingung. Sedangkan pada pemberian nilai dengan skor SUS merujuk pada rentang nilai yang sudah ditentukan sesuai pada gambar 8, (Rasmila, 2018) maka untuk grade $A$ dengan skor $>=80,3$, grade $B$ dengan skor $>=74$ hingga

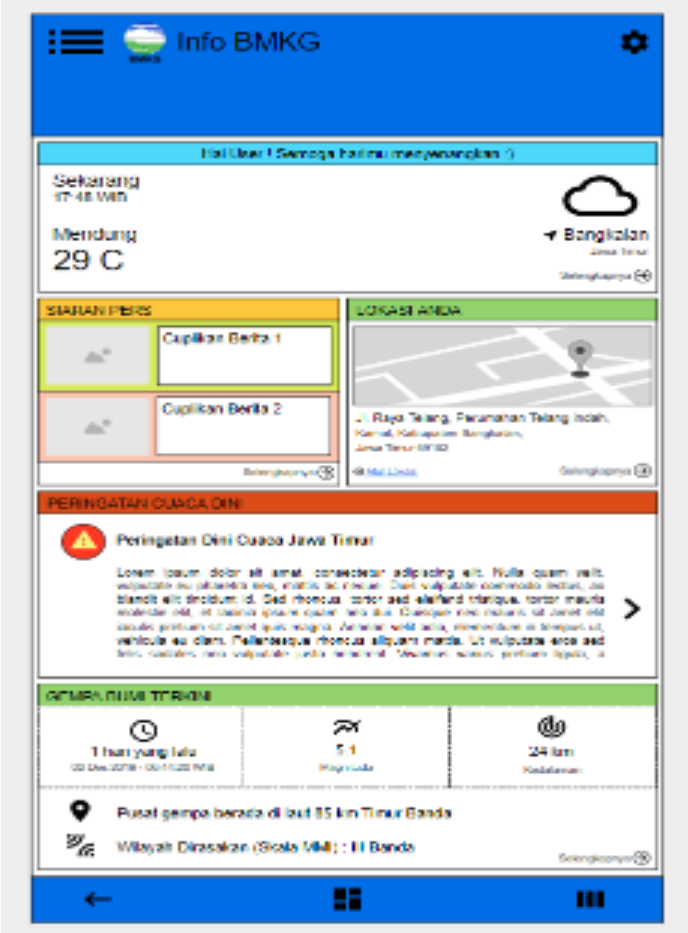

Gambar 9. Usulan Perbaikan Desain dashbord
$<80,3$, untuk Grade $C$ dengan skor $=>68$ hingga $<74$, grade D dengan skor $>=51$ sampai $<68$ dan Grade $F$ dengan skor $<51$. Sehingga dapat disimpulkan untuk penilaian usability dengan metode SUS pada Aplikasi Mobile BMKG dengan nilai 60 berada pada grade $D$, sehingga pada Tampilan Dashbord dan Menu Pengaturan/Setting masih diperlukan desain perbaikan lebih lanjut lagi.

Melihat hal tersebut maka disusulah usulan desain perbaikan dalam bentuk (Wireframe/ Low Fidelity Design) pada aplikasi mobile BMKG seperti pada gambar 9 .

\section{Informasi yang ditampilkan :}

- Pada tampilan dashboard yang telah kami rancang, kami tambahkan penekanan pada pilihan kategori agar tidak terlalu membingungkan user, ditampilkan sebanyak 4 kategori (dan 1 bagian khusus laman kecil status hari ini).

- Kategori terbagi atas Siaran Pers (untuk berita terkini), Lokasi anda (mengetahui lokasi kita saat ini), Peringatan cuaca dini (berisi tentang himbauan dari BMKG) dan Gempa bumi terkini.

\section{Yang bisa dilakukan User :}

- Dengan mengklik dropdown list, user dapat berpindah halaman sesuai dengan submenu yang dipilihnya.

- Dengan mengklik icon pengaturan, user dapat melakukan beberapa konfigurasi atau ingin mengetahui kebijakan aplikasi, selengkapnya akan ditampilkan dalam menu ini.

- Dengan mengklik atur lokasi, user dapat mengatur lokasi sesuai keinginan, jadi pengaturan lokasi sekarang berdiri sendiri tidak bercampur dengan pengaturan utama.

- Dengan mengklik selengkapnya pada masing - masing kategori mini, user akan diarahkan pada menu utama pada masing - masing kategori tersebut.

Sedangkan pada gambar 10 adalah menu Pengaturan usulan desain perbaikannya. 


\section{Informasi yang ditampilkan :}

- Terdapat 7 pilihan yang masing - masing memiliki akan menampilkan informasi yang berbeda - beda.

- Adapun opsi - opsi tersebut adalah Satuan, Format Jam dan Tanggal, Tampilan Tema, Developer, Syarat dan ketentuan, Privasi dan Tentang kami.

\section{Yang bisa dilakukan User :}

- Jika user memilih Satuan, maka akan muncul beberapa pilihan berupa radio button untuk setiap kategori satuan yg ingin dirubah, misalnya apakah untuk temperature, angina, tekanan dan banyak lagi.

- Jika user memilih format jam dan tanggal, maka akan muncul sebuah pilihan berupa radio button untuk masing - masing yang ingin dikonfigurasi, misalnya format waktunya atau format tanggalnya.

- Jika user memilih Tampilan Tema, akan muncul 2 radio button yang dapat mengubah memilih mode malam atau mode biasa.

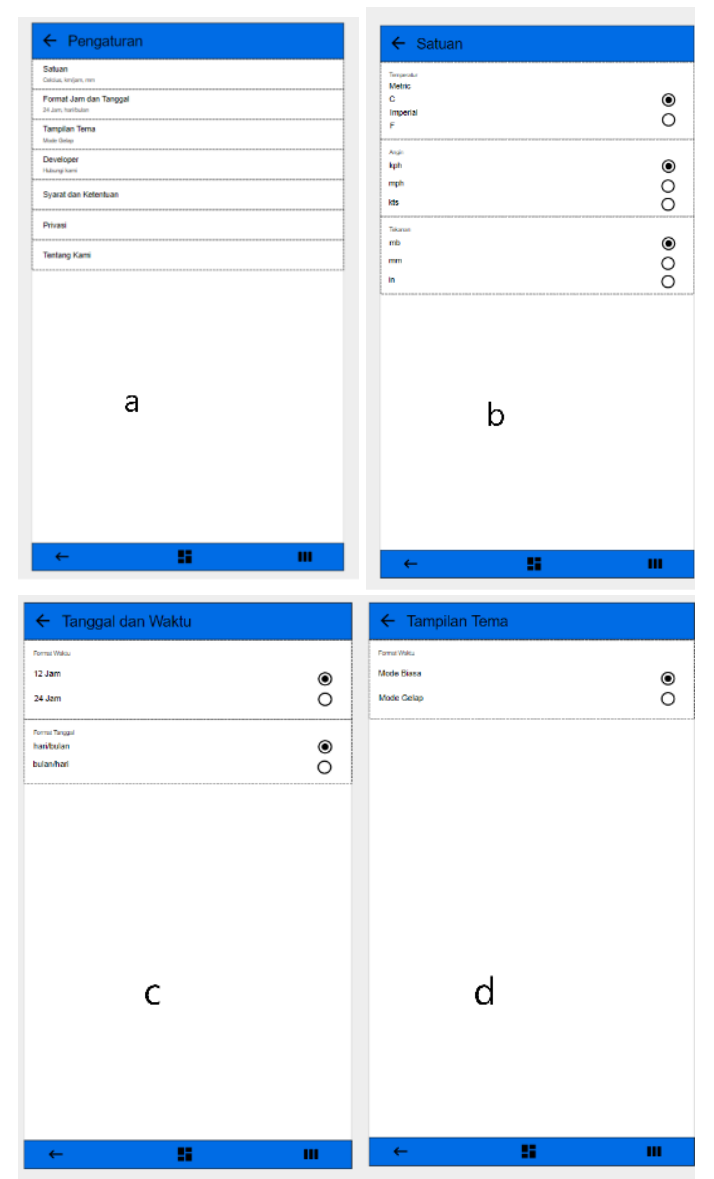

Gambar 10. Usulan desain pada menu pengaturan
- Jika user memilih Developer akan diarahkan pada aplikasi email dan alamat tujuan sudah langsung terisi email dari developer, user cukup mengisi apa yang menjadi keluh kesahnya dan mengirimkannya.

- Jika user memilih Syarat dan Ketentuan, seperti pada umumnya akan ditampilkan teks panjang mengenai kebijakan aplikasi.

- Jika user memilih privasi, di sana user akan diberikan pilihan apakah mereka bersedia memberikan data - data mengenai pemakainnya kepada pihak developer untuk keperluan imporvisasi aplikasi atau tidak.

- Jika user memilih about, akan ditampilkan detail mengenai siapa pembuat aplikasi tersebut.

Dari usulan desain yang terlah dibuat tersebut kita lakukan pengujian dengan metode Perhitungan SUS (System Usability Scale, dipereoleh hasil seperti pada tabel 5 berikut.

Tabel 5. Hasil penilaian perhitungan SUS ke 2 oleh Responden

\begin{tabular}{ccc}
\hline Responden & Jumlah & $\begin{array}{c}\text { Hasil Penilaian } \\
\text { (Jumlah } \mathbf{~ 2 . 5 )}\end{array}$ \\
\hline 1 & 35 & 90 \\
2 & 33 & 83 \\
3 & 28 & 70 \\
4 & 32 & 80 \\
5 & 32 & 80 \\
6 & 35 & 88 \\
7 & 35 & 88 \\
8 & 32 & 80 \\
9 & 30 & 75 \\
10 & 29 & 73 \\
Skor Rata-rata (Hasil & $\mathbf{8 0 , 2 5}$ \\
\multicolumn{2}{c}{ Akhir) } &
\end{tabular}

Melihat nilai dari hasil kuisioner dengan metode SUS dengan skor rata-rata 80,25 maka dapat disimpulkan bahwa :

1. Dilihat dari hasil kuisioner dengan skor ratarata yang didapat 80,25 mulai dari Acceptability Ranges, Grade Scale, Adjective Rating sebagai berikut : a) tingkat penerimaan pengguna masuk dalam kategori Acceptable, b). Tingkat grade skala masuk dalam kategori $B, c)$. Adjective rating masuk dalam kategori excellent. Sesuai dengan hasil penilaian tersebut maka usulan desain Aplikasi Mobile 
BMKG dapat diterima dengan baik serta dapat digunakan dengan mudah oleh user tanpa merasa bingung.

2. Sedangkan pada pemberian penilaian dengan metode SUS dari hasil feedback kuisioner oleh penggunan memperoleh skor 80,25 maka masuk grade $B$ dengan skor $>=74$ hingga $<80,3$.

Berdasarkan penilaian dengan metode SUS dari hasil feedback responden terhadap Aplikasi Mobile BMKG berada pada grade $B$, sehingga pada Aplikasi Mobile BMKG dapat diterima dan digunakan dengan mudah oleh pengguna, sehingga pengguna tidak merasa kebingungan terhadap desain hasil perbaikan dalam mendapatkan layanan informasi cuaca yang diberikan.

\section{SIMPULAN DAN SARAN}

Dari hasil penelitian yang sudah dijelaskan sebelumnya, maka dapat diambil kesimpulan bahwa desain aplikasi mobile BMKG yang sudah ada sebelumnya masih perlu dilakukan desain perbaikan terbukti dari hasil wawancara yang sudah dilakukan kepada para responden serta analisa sesuai dengan prinsip Eight Golden Rules dan juga telah dilakukan pengujian menggunakan metode perhitungan System Usability Scale mendapatkan nilai rata-rata 60 yang mana menunjukan untuk Acceptability Ranges masuk Marginal Low, Grade Scale masuk kategori D, untuk Adjective Rating masuk dalam grade $O K$, dari hasil penilaian yang didapat tersebut maka dilakukan usulan desain perbaikan terhadap aplikasi mobile tersebut sesuai dengan masukan yang telah didapatkan dari para responden kemudian dilakukan pengujian yang ke 2 dengan metode Perhitungan SUS (System Usability Scale) mendapatkan skor rata-rata 80,25 sehingga dapat disimpulkan untuk tingkat penerimaan pengguna masuk dalam kategori Acceptable, tingkat grade scale masuk dalam kategori B, Adjective rating masuk dalam kategori excellent. Sehingga usulan desain perbaikan pada Aplikasi Mobile BMKG dapat diterima dengan baik serta dapat digunakan dengan mudah oleh user tanpa merasa kebingungan untuk mendapatkan layanan informasi cuaca yang diberikan.
Untuk mengetahui bagaimana respon pengguna dalam menggunakan aplikasi mobile untuk penelitian selanjutnya dapat dilakukan hingga tahap User Experience (UX), sehingga dapat diketahui lebih luar lagi respon pengguna terhadap aplikasi baik dari segi interface juga dari segi fungsionalitasnya.

\section{DAFTAR PUSTAKA}

Akbar, G. S., Kaburuan, E. R., \& Effendy, V. (2018). User interface (UI) design of scheduling activity apps for autistic children. Proceedings of the 2017 International Conference on Orange Technologies, ICOT 2017, 2018-Janua, 129-133. https://doi.org/10.1109/ICOT.2017.83361 05

Akhsan, A. A., \& Faizah, F. (2017). Analisis dan Perancangan Interaksi Chatbot Reminder dengan User-Centered Design. Jurnal Sistem Informasi, 13(2), 78. https://doi.org/10.21609/jsi.v13i2.555

Bangor, A., Staff, T., Kortum, P., Miller, J., \& Staff, T. (2009). Determining what individual SUS scores mean: adding an adjective rating scale. Determining What Individual SUS Scores Mean: Adding an Adjective Rating Scale, 4(3), 114-123.

BMKG. (2016). Panduan Pengguna Aplikasi Mobile Info BMKG. Bmkg.Go.Id, 1. Retrieved from http://apps.bmkg.go.id/panduan/android /

Brooke, J. (2014). SUS - A quick and dirty usability scale. Journal of Drugs in Dermatology, 13(5), 531-536. https://doi.org/10.4236/9781618961020_ 0002

Fanani, Lutfi, Ananta Tri , Mahardeka, Candra Brata, K. (2018). Penerapan User-Centered Design dalam Pengembangan Aplikasi Pencarian Gedung Berbasis Android. Cybernetics, 2(02), 225. https://doi.org/10.29406/cbn.v2i02.1156

Farooqui, T., \& Rana, Tauseef, Jafari, F. (2019). Impact of Human-Centered Design Process (HCDP) on Software Development Process. 2019 2nd International Conference on Communication, Computing and Digital Systems, C-CODE 2019, 110114. 
Forte, Jonas, Darin, T. (2017). User Experience Evaluation for User Interface Redesign: A Case Study on a Bike Sharing Application. Lecture Notes in Computer Science (Including Subseries Lecture Notes in Artificial Intelligence and Lecture Notes in Bioinformatics), 10290 LNCS, 347-356. https://doi.org/10.1007/978-3-31958640-3_44

Handiwidjojo, W., \& Ernawati, L. (2016). Pengukuran Tingkat Ketergunaan ( Usability ) Sistem Informasi Keuangan Studi Kasus: Duta Wacana Internal Transaction ( Duwit ). Juisi, 02(01), 49-55.

Jelita Ardhiyani, A. M. B. (2015). Analisis User Interface Media Pembelajaran Pengenalan Kosakata Untuk Anak Tunarungu. Jurnal Ilmiah Komputer Dan Informatika (KOMPUTA), 45-53.

Junus, I. S., Santoso, H. B., Isal, R. Y. K., \& Utomo, A. Y. (2015). Usability evaluation of the student centered e-Learning environment. International Review of Research in Open and Distance Learning, 16(4), 62-82. https://doi.org/10.19173/irrodl.v16i4.2175

Laily, A. N., Rokhmawati, R. I., \& Herlambang, A. D. (2018). Evaluasi dan Perbaikan Desain Antarmuka Pengguna Menggunakan Pendekatan Human-Centered Design (HCD) ( Studi Kasus: Djarum Beasiswa Plus ). Jurnal Pengembangan Teknologi Informasi Dan Ilmu Komputer (J-PTIIK) Universitas Brawijaya, 2(9).

Nurhadryani, Y., Sianturi, S. K., Hermadi, I., \& Khotimah, H. (2013). Pengujian Usability untuk Meningkatkan Antarmuka Aplikasi Mobile. Jurnal Ilmu Komputer Dan AgriInformatika, 2(2), 83. https://doi.org/10.29244/jika.2.2.83-93

Rahadi, D. R. (2014). Pengukuran Usability Sistem Menggunakan Use Questionnaire Pada Aplikasi Android. 6(1), 661-671.

Rasmila. (2018). Evaluasi Website Dengan Menggunakan System Usability Scale (SUS) Pada Perguruan Tinggi Swasta Di Palembang. JUSIFO: Jurnal Sistem Informasi, 02(Vol 2 No 1 (2018): JUSIFO), 108-121. Retrieved from http://jurnal.radenfatah.ac.id/index.php/ju sifo/article/view/2445
Sabandar, V. P., \& Santoso, H. B. (2018). Evaluasi Aplikasi Media Pembelajaran Statistika Dasar Menggunakan Metode Usability Testing. Teknika, 7(1), 50-59. https://doi.org/10.34148/teknika.v7i1.81

Santoso, H. B., Schrepp, M., Yugo Kartono Isal, R., Utomo, A. Y., \& Priyogi, B. (2016). Measuring user experience of the studentcentered E-learning environment. Journal of Educators Online, 13(1), 1-79.

Sharfina, Z., \& Santoso, H. B. (2017). An Indonesian adaptation of the System Usability Scale (SUS). 2016 International Conference on Advanced Computer Science and Information Systems, ICACSIS 2016, 145-148.

https://doi.org/10.1109/ICACSIS.2016.787 2776

Shneiderman B., P. C. C. M. J. S. E. N., \& Diakopoulos, N. (2016). Designing the User Interface: Strategies for Effective Human-Computer Interaction, 6th Edition. JASIST, 61, 1073-1074. https://doi.org/10.1002/asi.21215

Wardhana, S. R., Purwitasari, D., \& Rochimah, S. (2016). Analisis Sentimen Pada Review Pengguna Aplikasi Mobile Untuk Evaluasi Faktor Usability. Jurnal Sistem Dan Informatika, 11(1), 128-136. Retrieved from http://jsi.stikombali.ac.id/index.php/jsi/article/view/96/88

Wedayanti, N. L. P. A., Wirdiani, N. K. A., \& Purnawan, I. K. A. (2019). Evaluasi Aspek Usability pada Aplikasi Simalu Menggunakan Metode Usability Testing. Jurnal MERPATI, 7(2), 113-124.

Yatana Saputri, I. S., Fadhli, M., \& Surya, I. (2017). Penerapan Metode UCD (User Centered Design) Pada E-Commerce Putri Intan Shop Berbasis Web. Jurnal Nasional Teknologi Dan Sistem Informasi, 3(2), 269278.

https://doi.org/10.25077/teknosi.v3i2.201 $7.269-278$ 